\title{
BIOLOGY OF GRAM BLUE BUTTERFLY, EUCHRYSOPS CNEJUS (FABRICIUS) (LYCAENIDAE: LAPIDOPTERA) AND ITS RELATIONSHIP WITH THE PHENOLOGY OF HOST-PLANT (VIGNA UNGUICULATA: FABACEAE)
}

\author{
SAJEDA AKAND, M.A. BASHAR ${ }^{*}$ AND HUMAYUN REZA KHAN
}

Environmental Biology and Biodiversity Laboratory, Department of Zoology, University of Dhaka, Dhaka-1000, Bangladesh

\begin{abstract}
The biology of the gram blue butterfly, Euchrysops cnejus (Fabricius) (Lycaenidae: Lapidoptera) and its relationship with the phenology of host plant cowpea, Vigna unguiculata L. (Fabaceae) were studied. Eggs were reared under the laboratory conditions at $28 \pm 2{ }^{\circ} \mathrm{C}$ and $74 \pm$ $3 \% \mathrm{RH}$. The incubation period of the eggs found to be $2.33 \pm 0.51$ days, larval developmental period $14.65 \pm 0.51$ days, pre-pupal period $0.30 \pm 0.04$ day and pupal period $5.66 \pm 0.51$ days. The species took $22.94 \pm 0.55$ days for development from egg to adult under the laboratory condition. The length of $1^{\text {st }}, 2^{\text {nd }}, 3^{\text {rd }}$ and $4^{\text {th }}$ instar larvae was $3.66 \pm 0.40,6.16 \pm 0.51,12.16 \pm 0.51$ and 15.33 $\pm 0.40 \mathrm{~mm}$, respectively. The pre-pupal length was $9.16 \pm 0.61 \mathrm{~mm}$ and the pupal length was $9.08 \pm$ $0.37 \mathrm{~mm}$. The host-plant occurs in the field from February to July. The butterfly appeared in March. The coincidence of the gram blue butterfly to its host-plant occurred between April and early July. The oviposition behaviour, incubation and immature stages were found to be profoundly related with host plant-phenological phases.
\end{abstract}

Key words: Developmental stages, Euchrysops cnejus, Relationship, Vigna unguiculata, Host-plant, Phenology

\section{INTRODUCTION}

Phytophagous insects have the strong interaction with their natural host plants, and a particular host plant choice is an important step in the life-cycle (Rabasa et al. 2005, Janz et al. 2005). A butterfly grows and develops as a feeding caterpillar, inactive pupa and emerges as an adult; the female spends much time and energy in mating, egg production and in finding suitable food plant(s) on which to lay her eggs (Braby 1994). The process of host plant selection by insects is governed primarily by volatile chemical signals, later by visual stimuli, and finally by non-volatile chemical signals (Hern et al. 1996). Most lycaenid butterflies are phytophagous and their larvae are external feeders, either eating whole plant tissues or organs (flower buds, flowers and fruits) or skeletonising foliage (New 1993).

\footnotetext{
* Corresponding author: <m.abulbashar@gmail.com>.
} 
Euchrysops cnejus (Fabricius) (Lycaenidae: Lapidoptera) is commonly known as the gram blue butterfly. The members frequent in the localised areas and appear at any time of the year depending on the availability and condition of their food plants. The life stages of gram blue butterfly are associated with different phonological phases of larval food plant, Vigna unguiculata. It is commonly known as yard-long bean, cowpea, blackeye bean or catjang and locally as Borboti.

Cowpeas are an annual summer-growing climbing, herbaceous, prostrate, or suberect to erect legume. In Bangladesh, it is cultivated in many parts. This plant can be grown in dry lands all the year round according to different seed variety (Ahmed et al. 2009). Seeds are sown at $2 \mathrm{~cm}$ depth into prepared bed during February to March. Three to five days after sowing seedlings begin to emerge from soil and flower appears within 70 - 90 days. Cowpea crops mature within 80 - 110 days after sowing. Tender pods should be harvested before they become fibrous and the harvesting period ranges from May to July. The plant is harvested for fodder or is used as green manure, when they start bearing flowers.

The present study emphasized on the relationship between the developmental stages of the gram blue butterfly, E. cnejus and the phenology of its host plant $V$. unguiculata. This relationship helps to know the species abundance of both plant and butterfly in an area. It is felt that prior to examine plant-butterfly association in an area, it is essential to take necessary steps for preventing species decline and increasing species richness. This study may be helpful in conserving floral and faunal assemblages and nature conservation.

\section{MATERIALS AND METHODS}

The eggs of Euchrysops cnejus were collected after laying on Vigna unguiculata plant by female butterflies between 10 a.m. and 12 p.m. from the Germplasm Centre (GPC) of

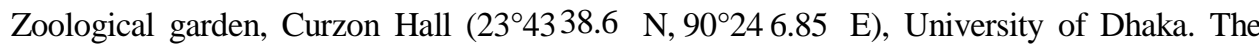
egg-laying behaviours of the butterfly species and its host plant's phenology as well as their relationship were observed in the GPC. The seeds of cowpea were sown from the last of January to March in the study area. Within one week seedling emerged from the soil. Flowers appeared at mid April and continued to early July. At the same time fruitification started. The harvesting period remains at the end of July. The gram blue butterfly appears from March, lay eggs on flower buds or young leaves during this period. Coincidence of gram blue butterfly to its host plant happened from April and continues to the early of July (Table 1). The metamorphosis of the different developmental stages of the butterfly was observed in an ambient environment of the Environment Biology and Biodiversity Laboratory (EBBL), Department of Zoology, University of Dhaka. The butterfly and its host plant species were identified following Eliot (1973) and Ahmed et al. (2009), respectively. 
The larvae hatched from collected eggs were reared in a rectangular plastic box $(36 \times$ $30 \times 15 \mathrm{~cm}$ ). They were given the leaves and fruits of the host plants as their foods. Larval moulting took place within the box. The larvae pupated inside the rearing box. The inactive pupae with rearing box were shifted into a bigger rectangular and iron-rod framed adult emergence cabinet $(53 \times 46 \times 92 \mathrm{~cm})$ being covered all sides with mosquito net so that the newly emerged butterfly cannot fly away. The pupae inside the plastic box were left in the emergence cabinet undisturbed until adult emergence. Larval food was supplied every alternative day. The rearing boxes containing the larvae were cleaned daily by sterilized brush, forceps, sprayer, scissor etc. for keeping the larvae free from fungal infections.

Table 1. Coincidence of butterfly life cycle and its host plant phenology.

\begin{tabular}{l}
$\begin{array}{l}\text { Month Jan Feb Mar Apr May Jun Jul Aug Sep Oct } \\
\text { Life cych }\end{array}$ \\
$\begin{array}{l}\text { Butterfly } \\
\text { Host plant }\end{array}$ \\
\hline
\end{tabular}

Pertinent data were recorded every morning. Larval length was measured with a measuring scale. The duration of different larval instars was recorded. The data were analyzed statistically. The biology of the species was studied following Baker (1984).

\section{RESULTS AND DISCUSSION}

Butterflies demonstrate a hierarchy in host preferences, discriminating among plant species, among genotypes, among individuals with different phenological and physiological conditions, and even among plant parts (Wiklund 1984). The developmental stages of gram blue butterfly have been examined in laboratory. The relationship between gram blue butterfly and its host-plant has also been observed in this experiment. Life cycle of Euchrysops cnejus (Fig. 1) starts through mating following egg laying and consists of egg, four instars of larva, pre-pupa, pupa and ends as adult.

Males are seen to slowly flutter beneath the food plant looking for newly emerged females with which to mate. Males have unusual long, hair-like scales on the dorsal sides of the wings which comprises androconia. These are specialised wing scales on the dorsal sides of the wings used for courtship. At the time of mating they do not fly because of the overweight of female abdomen. During the study, it was found that duration of mating period was 40 - 50 minutes.

Gram blue butterfly vibrates its wings rapidly and repeatedly visit the plants when it searches host plants. It bends abdomen to touch the plant parts for searching host plants and moves forward. Finding a suitable place it lays egg. Mostly eggs are laid on particular plant species or plant parts at climatically favourable spots (Strausz 2010). It 
lays eggs singly and after laying one egg it flies away to take rest for sometimes, then start to lay next egg. In this way this butterfly lays several eggs at day light.

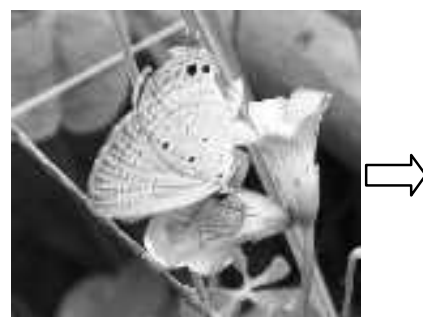

A. Adult butterfly

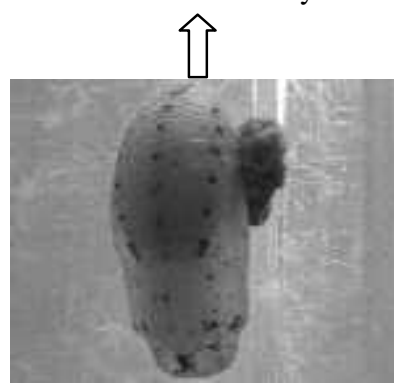

J. Pupa

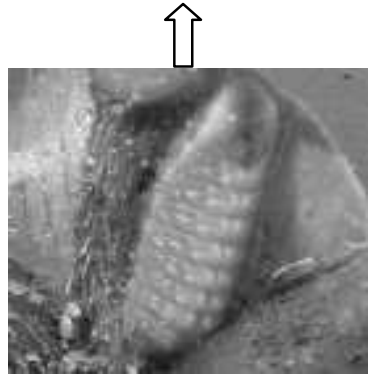

I. Pre-pupa

仓

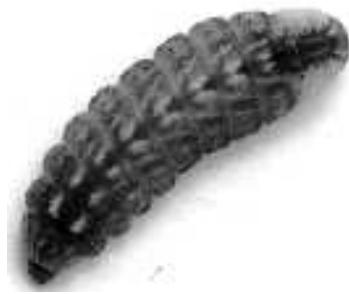

H. Fourth instar larva

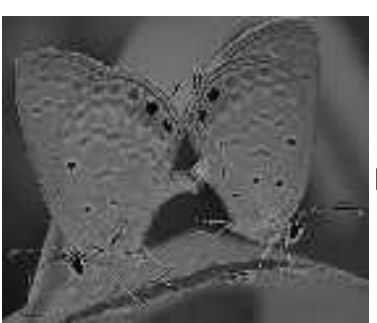

B. Mating

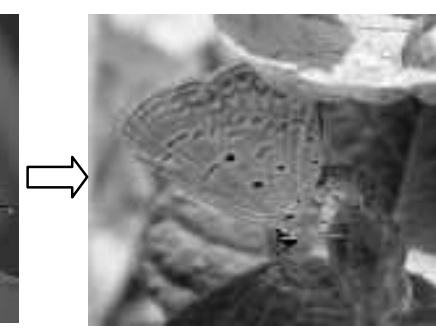

C. Egg-laying

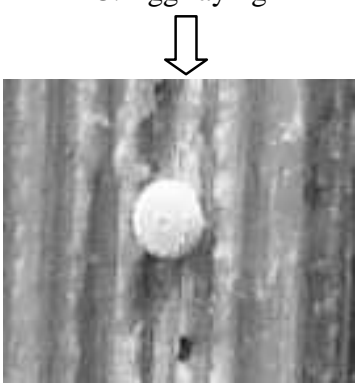

D. Egg

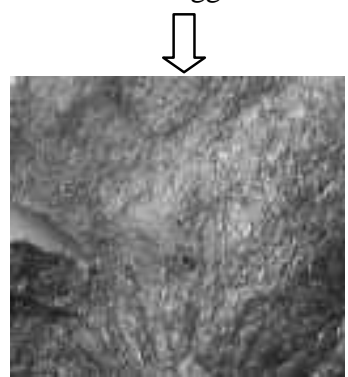

E. First instar larva

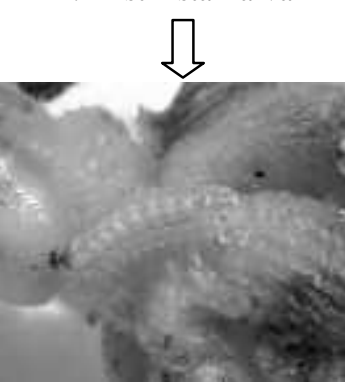

F. Second instar larva

Fig. 1. Life cycle of Euchrysops cnejus.

The eggs of E. cnejus (Fig. 1D) are small, disc-like and hemispherical, strongly flattened top and bottom, slightly depressed on top with a small darker central micropylar 
area. The eggs are laid on young shoots, flower buds or leaves of the host plants. Freshly laid egg is yellowish green in colour. It decolourizes soon to light green within the next day and turns to a blue-white within a few days. Mature eggs are white in colour. The eggs are ornamented with short blunt spines on the side, which are absent on the top of the egg. The reticulation facets are trigonal, which are grouped together in an orderly fashion to form large hexagons. The facets on the top of the egg are much smaller and are of irregular shape. The egg hatched within 2 to 3 days.

The first instar larva (Fig. 1E) comes out from the egg after nibbling away sufficiently large portion of the egg shell. The freshly emerged larva is pale yellow in colour with moderately long fine setae. It has cylindrical body with a black head capsule with a dark pro-thoracic shield. The newly hatched larva is about 1.3 to $1.5 \mathrm{~mm}$ in length. It makes its way to a flower bud and starts to bore into it. First instar larva stays within the flower bud and feeds on the flower parts. After 3 - 4 days of development, it reaches 4 $\mathrm{mm}$ in length and changes its colour to yellowish brown and moults into the next instar. Moulting from first instar to second instar typically takes place within the flower bud.

The second instar larva (Fig. 1F) is pale yellowish brown in colour and more transparent, sometimes reddish brown bands run dorsally. The head capsule is black with a dark-coloured pro-thoracic shield. The body is now more woodlouse-like in shape. The larva maintains the habit of boring into flower buds and feeding them from within. A mature second instar larva reaches to a length of $5-7 \mathrm{~mm}$. It moults to the next instar larva after about 4 - 5 days development.

The third instar larva (Fig. 1G) shows reddish brown colour with deep reddish dorsal line. The head capsule is still black, but the pro-thoracic shield decolorized to the body base colour. Both the dorsal nectary organ and the tentacular organs are discernible at this stage. This larva migrates from flower parts to seed pods to eat developing seeds within it. A fully grown larva is blackish red in colour with a blackish dorsal line. After reaching about $11-13 \mathrm{~mm}$ in body length, the third instar larva takes $3-4$ days to moult into the fourth instar larva.

The fourth or final instar larva (Fig. 1H) is green with a reddish brown dorsal line and yellowish green posterior end. The nectary organs are rather prominent in this instar. After 3 days, this larva reaches a maximum body length of about $15-16 \mathrm{~mm}$ and ceases development for next moult. The body of larva is covered with fine hairs. The larvae feed openly during the day, but are usually hidden within the flowers or seed pods. The presence of larvae on the food plant is readily discernible by holes in the buds, flowers and seed pods. These larvae, like most lycaenid larvae are able to extend their heads considerably and are able to eat out the seed contents of a pod by protruding the head inside the hole made at the side of the pod, while the rest of the body remains outside the pod. 
After 14 - 15 days of larval growth and reaching the maximum length of $15-16 \mathrm{~mm}$, the body of final instar larva gradually shrinks. The larva ceases eating and wanders around a passable pupation site. It chooses to enter its pre-pupatory phase on a spot of the leaf surface within a pile of withered leaves. Then, the larva prepares itself for pupation by spinning a silk girdle and a silk pad. Some larvae also choose to pupate within seed pods. In laboratory, the duration of pre-pupal phase (Fig. 1I) was about $6-8 \mathrm{hrs}$ and its length $9-10 \mathrm{~mm}$.

Pupation takes place on the same day when pre-pupal stage appears. Hairy pupa (Fig. $1 \mathrm{~J})$ has a typical lycaenid shape, beige in base colour with many black to dark brown patches on the pupal surface. The pupa of E. cnejus does not secure itself with cremastral hooks. It is about $9 \mathrm{~mm}$ long and pale green colour with black spots. Five days later, the pupa becomes dark coloured signalling the emergence of adult. Next day, adult butterfly emerges from the mature pupa. In the laboratory, the pupa took about 6 days to moult into adult.

Table 2. Length and duration of the immature stages of Euchrysops cnejus in an abient environment of the laboratory (Temp. $28 \pm 2^{\circ} \mathrm{C}$ and $74 \pm 3 \% \mathrm{RH}$ ).

\begin{tabular}{|c|c|c|c|c|}
\hline \multirow[t]{2}{*}{ Immature stages } & \multicolumn{2}{|c|}{ Length (mm) } & \multicolumn{2}{|c|}{ Stage duration/incubation (in days) } \\
\hline & Mean \pm Sd & Range & Mean \pm Sd & Range \\
\hline Egg & & & $2.33 \pm 0.516$ & $2-3$ \\
\hline \multicolumn{5}{|l|}{ Larva } \\
\hline $1^{\text {st }}$ instar & $3.66 \pm 0.408$ & $3.0-4.0$ & $3.33 \pm 0.516$ & $3-4$ \\
\hline $2^{\text {nd }} ״$ & $6.16 \pm 0.516$ & $5.5-7.0$ & $4.33 \pm 0.516$ & $4-5$ \\
\hline $3^{\text {rd }} ״$ & $12.16 \pm 0.516$ & $11.5-13$ & $3.33 \pm 0.516$ & $3-4$ \\
\hline $4^{\text {th }} "$ & $15.33 \pm .408$ & $15-16$ & $3.66 \pm 0.516$ & $3-4$ \\
\hline Total larva & & & $14.65 \pm 0.516$ & $14-15$ \\
\hline Pre-pupa & $9.16 \pm 0.616$ & $8.5-10$ & $0.30 \pm 0.041$ & $0.25-0.33$ \\
\hline Pupa & $9.08 \pm .376$ & $8.5-9.5$ & $5.66 \pm 0.516$ & $5-6$ \\
\hline Emarge as adult & & & $22.94 \pm 0.556$ & $22.25-23.33$ \\
\hline
\end{tabular}

The adult (Fig. 1A) emerges from the pupa by splitting open the case vertically on the dorsal side and emergence time requires about one hour. The adults are dimorphic, males and females being different. The male adult butterfly is pale purplish suffused with a bluish shade. The female has a dark brown colour tinted with irridescent blue at basal half, except broad coastal margins of both wings. Both the sexes have a filament-like tail on the outer margin of hind wings. They bear two black spots on each tail but in case of the females a sub terminal arc present on black spots. Ventrally, they are very similar, having a pale brown background with the usual lycaeninae markings as spots and striae. There is a pair of small black spots in the outer margin of hind wing, with a small band of metallic green scales inwardly crowned with orange colour (Ek-Amnuay 2006). In the laboratory, total duration from egg to adult emergence was found to be 21 - 23 days. 
During rearing, it was found that among the ten eggs, six hatched and completed their metamorphosis and emerged as adult butterfly. Mean length and stage of duration of different immature butterfly, such as larval instars, pre-pupa and pupa are shown in Table 2. Under the laboratory conditions, incubation period was 2 - 3 days and required average 22.94 days from egg hatching to adult emergence.

The immature stages of butterfly are radically different from each other. Life cycle changes in butterflies are deeply related with the phenology of host plants (Bashar 2010). Along with the growth of host plant, E. cnejus complete about 2 - 3 generations. High abundance of this butterfly was observed from April to June. Appropriate egg laying sites and thus larval habitats are of imminent importance for the persistence of butterfly populations (Strausz 2010). Thus, the relationship between any given butterfly species and its host plant is very specific.

There was a distinct synchronization between reproductive stages of $V$. unguiculata and developmental stages of E. cnejus. Larvae were found to consume flower buds and young fruits (pods) as food sources. This coincidence between two biotic factors (plant and butterfly) is essential for the completion of their life cycle successfully. The knowledge of butterfly-host plants and the relationship of plant-butterfly is a prerequisite for any butterfly conservation as well as biodiversity conservation programme (Tiple et al. 2010).

\section{ACKNOWLEDGEMENTS}

The authors gratefully acknowledge the authority of the University Grants Commission of Bangladesh, Directorate of Secondary and Higher Education, Bangladesh, and Ministry of Education, Government of the People's Republic of Bangladesh for their support to carry out this research work.

\section{REFERENCES}

Ahmed, J.U., M.A. Hassan, Z.N.T. Begum and M. Khondker. 2009. Encyclopedia of Flora and Fauna of Bangladesh. Vol. 6-12. Asiatic Society of Bangladesh, Nimtali, Dhaka 1000.

Baker, R.R. 1984. The Biology of Butterflies. Royal Entomological Society of London. Academic Press, London. pp. 279-296.

Bashar, M.A. 2010. Butterflies: Best 'biotic indicators' of climatic change. The Daily Star (Environment) 20(17): 13.

Braby, M.F. 1994. Life history strategies of tropical satyrine butterflies in north eastern Australia. Ph. D. thesis. Department of Zoology, James Cook University of North Queensland, Australia. pp. 315.

Ek-Amnuay, P. 2006. Butterflies of Thailand, Fascinating Insects. Amarin Printing and Publishing Public Co. Ltd., Bangkok 2: 523-718.

Eliot, J.N. 1973. The higher classification of the Lycaenidae (Lepidoptera): A tentative Arrangement. Bull. Brit. Mus. (Nat. Hist.), Ent. 28(6): 371-505. 
Hern, A., G. Edwards and R. Mckinlay. 1996. A review of the pre-oviposition behaviour of the small cabbage white butterfly, Pieris rapae (Lepidoptera: Pieridae). Annals of Applied Biology 128: 349-371

Janz, N., A. Bergstrom and A. Sjogren. 2005. The role of nectar sources for oviposition decisions of the common blue butterfly Polyommatus icarus. Oikos. 109: 535-538.

New, T.R. 1993. Intoduction to the biology and conservation of the Lycaenidae. Conservation Biology of Lycaenidae (Butterlfies) (Ed. New, T. R.), IUCN, Gland, Switzerland. pp. 1-174.

Rabasa, S.G., D. Gutie'Rrez and A. Escudero. 2005. Egg laying by a butterfly on a fragmented host plant: a multi-level Approach. Ecography 28(5): 629-/639.

Strausz, M. 2010. Habitat and host plant use of the large copper butterfly lycaena dispar rutilus (Lepidoptera: Lycaenidae) in Vienna (Austria). Diploma Thesis. University of Vienna, Austria. pp. 1-40.

Tiple, A.D., A.M. Khurad and R.L.H. Dennis. 2010. Butterfly larval host plant use in a tropical urban context: Life history associations, herbivory, and landscape factors. J. Insect Sci. 11(65): $1-21$.

Wiklund, C. 1984. Egg-laying patterns in butterflies in relation to their phenology and the visual apparency and abundance of their host plants. Oecologia 63(1): 23-29.

(Received revised manuscript on 29 October, 2015) 